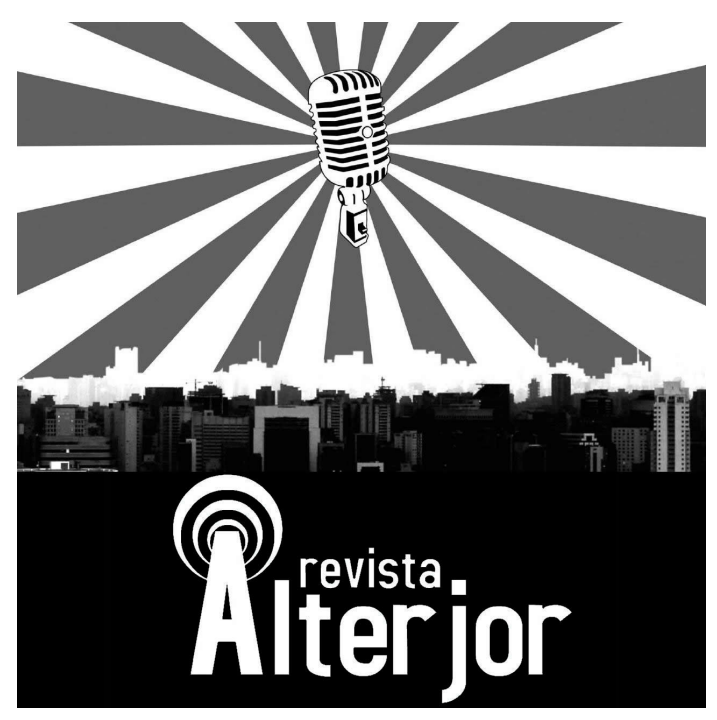

$\underline{\text { RESENHA }}$

\title{
JORNALISMO DAS PERIFERIAS: UM FENÔMENO EM EBULIÇÃO
}

\author{
Juliana Freire Bezerra ${ }^{1}$
}

\begin{abstract}
RESUMO: Jornalismo das Periferias: o diálogo social solidário nas bordas urbanas resulta de pesquisa de campo realizada entre 2018 e 2019 nas periferias da Região Metropolitana de São Paulo. Escrita pela pesquisadora e professora Mara Rovida, a obra origina-se da inquietação epistemológica diante de um fenômeno comunicacional recente no Brasil: o jornalismo profissional feito sobre, para e a partir das periferias. O objetivo principal da jornada de pesquisa relatada no livro foi compreender como os profissionais do Jornalismo das Periferias atuam para produzir narrativas polissêmicas e polifônicas sobre as localidades onde moram em sua relação com a cidade. Inspirada na abordagem etnográfica de Clifford Geertz, a autora parte dos sentidos atribuídos pelos sujeitos de pesquisa para interpretar o fenômeno estudado e sistematizar suas características.
\end{abstract}

PALAVRAS-CHAVE: Profissão. Jornalismo. Periferias.

ABSTRACT: Journalism of the Peripheries: the solidarity social dialogue in the urban borders results from a field research carried out between 2018 and 2019 in the peripheries of the São Paulo Metropolitan Region. Written by the researcher and professor Mara Rovida, the work originates from the epistemological restlessness in the face of a recente communicational phenomenon in Brazil: professional journalism done on, for and from the peripheries. The main objective of the research Journey reported in the book was to understand how professionals in Journalism of the Peripheries work to produce polysemic and polyphonic narratives about the locations where they live and the city as a whole. Inspired by Clifford Geertz's ethnographic approach, the author uses the meanings atributes by the research subjects to interpret the fenômeno studied and systematize its characteristics.

KEYWORDS: Profession. Journalism. Peripheries.

\footnotetext{
${ }^{1}$ Doutoranda do Programa de Pós-Graduação em Jornalismo (PPGJOR) da Universidade Federal de Santa Catarina. Pesquisadora do Observatório da Ética Jornalística (objETHOS), grupo de pesquisa do Programa de Pós-Graduação em Jornalismo da UFSC. Jornalista responsável pelo projeto de extensão Jornalismo e Ação Comunitária do Departamento de Jornalismo da UFSC. E-mail: freire.juliana.bez@gmail.com
}

\section{Revista ALTERJOR}

Grupo de Estudos Alterjor: Jornalismo Popular e Alternativo (ECA-USP)

Ano 11 - Volume 02 - Edição 24 - Julho-Dezembro de 2021

Av. Professor Lúcio Martins Rodrigues, 443, Cidade Universitária, São Paulo, CEP: 05508-020 


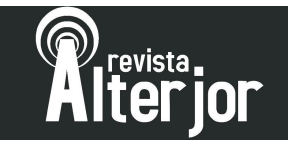

O Jornalismo Profissional produzido por Sujeitos Periféricos é um fenômeno recente no Brasil. Oriundo de fatores multicausais, relaciona-se em grande medida ao fenômeno mais amplo da consolidação de políticas públicas inclusivas no que concerne o acesso ao Ensino Superior por cidadãos historicamente excluídos dos espaços formativos das universidades. Compreender como jornalistas profissionais oriundos das periferias atuam há cerca de uma década para criar e gerir arranjos alternativos à mídia corporativa, produzindo narrativas que evidenciam a polifonia e a polissemia dos territórios periféricos em sua relação com a cidade é o objetivo da pesquisadora Mara Rovida em Jornalismo das Periferias: o diálogo social solidário nas bordas urbanas.

A obra publicada em 2020 pela editora CRV, resulta de pesquisa de campo realizada entre 2018 e 2019, cujo cenário é composto pelas periferias de São Paulo. Em linguagem fluida, mas sem perder a densidade requerida em trabalhos acadêmicos, o livro ancora-se no esforço de relatar e interpretar os sentidos atribuídos pelos sujeitos de pesquisa sobre a prática profissional que assumem à frente de iniciativas de Jornalismo das bordas urbanas. Além disso, recorre-se à técnica da observação para complementar a análise sobre rotinas produtivas e produção de pautas.

Como recorte de pesquisa, a autora opta por analisar quatro arranjos alternativos às corporações de mídia ligados à Rede Jornalistas das Periferias, que abarca em um amplo grupo formativo e de apoio diversas iniciativas com esse perfil na Região Metropolitana de São Paulo - RMSP. Agência Mural de Jornalismo das Periferias, Alma Preta, Nós, Mulheres da Periferia e Periferia em Movimento foram os arranjos selecionados e seis jornalistas vinculados a esses grupos configuram-se ao longo do livro como fontes de informação e personagens do relato.

A técnica do diário de campo constitui-se como recurso narrativo utilizado para costurar as informações coletadas por meio de observação e das entrevistas. Desses dados, a autora parte para empreender a reflexão teórica, ancorando-se em grande medida nos autores e discussões acadêmicas mencionados pelos jornalistas. O esforço metodológico, inspirado na abordagem etnográfica do antropólogo norte-americano Clifford Geertz,

\section{Revista ALTERJOR}

Grupo de Estudos Alterjor: Jornalismo Popular e Alternativo (ECA-USP)

Ano 11 - Volume 02 - Edição 24 - Julho-Dezembro de 2021 Av. Professor Lúcio Martins Rodrigues, 443, Cidade Universitária, São Paulo, CEP: 05508-020 


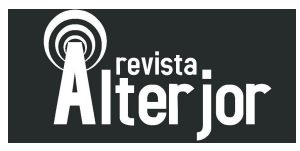

objetiva compreender o que motiva os sujeitos de pesquisa a criarem as iniciativas de comunicação das periferias e como materializam esse processo.

As escolhas de pesquisa são detalhadas no capítulo A Descoberta, o primeiro dos cinco que compõem o livro. Nele, a autora conta que a sua curiosidade epistemológica sobre o fenômeno estudado derivou de um debate sobre Gênero e Jornalismo promovido pelas Faculdades Integradas Rio Branco, na capital paulista, quando a jornalista Lívia Lima, vinculada ao Nós, Mulheres da Periferia, explicou que o jornalismo produzido pelo grupo de profissionais mulheres não possuía apenas um recorte de gênero, mas também de território.

Envolta pelo interesse de conhecer mais sobre essa iniciativa, Mara Rovida descobriu outras tantas que tomavam o território periférico como marcador identitário de quem produz, é fonte, público e personagem das matérias. Segundo a autora, além do acesso mais democratizado à universidade e das possibilidades tecnológicas atuais, parte do crescimento desse fenômeno atrela-se à dificuldade de inserção desses profissionais no mercado de trabalho, em virtude de fatores diversos, incluindo a desigualdade de oportunidades para desenvolver algumas competências paralelas requeridas na profissão, como a fluência em outros idiomas. O fenômeno também se associa à busca desses profissionais por evidenciarem a complexidade e pluralidade das realidades onde moram, uma vez que as periferias se encontram historicamente à margem da produção noticiosa feita pela imprensa comercial e comumente são estigmatizadas como lugares apenas de carestia e violência nas narrativas sociais circulantes.

Dotados de saberes corporificados pela experiência de vida nos territórios periféricos e dos conhecimentos técnicos, éticos e estéticos da profissão, os jornalistas das iniciativas estudadas ajudam a desconstruir os estereótipos que espoliam seus moradores, ao passo que enunciam a dinâmica e pluralidade cultural, cidadã, política, econômica que existem nessas realidades. Além disso, denunciam a violação de direitos que marca a trajetória de vida desses cidadãos, enquanto moradores de territórios distantes do centro, isto é, de onde o Estado se faz presente.

\section{Revista ALTERJOR}

Grupo de Estudos Alterjor: Jornalismo Popular e Alternativo (ECA-USP)

Ano 11 - Volume 02 - Edição 24 - Julho-Dezembro de 2021 Av. Professor Lúcio Martins Rodrigues, 443, Cidade Universitária, São Paulo, CEP: 05508-020 


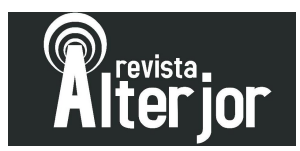

Tendo em vista que um dos pré-requisitos para trabalhar nessas iniciativas é ser um morador da periferia, o segundo capítulo do livro - A periferia pelos periféricos - é destinado a entender quais significados esses jornalistas atribuem ao "Ser Periférico" e aos territórios onde moram. Além disso, Mara Rovida mobiliza autores citados pelos entrevistados, como Tiarajú Pablo D’Andrea, que fundamenta a noção de Sujeito Periférico, enquanto sujeito histórico e promotor da transformação social, bem como autores de outras áreas, a exemplo do geógrafo brasileiro Milton Santos, para discutir o conceito de território e compreender o lócus de atuação desses jornalistas, a RMSP.

Ancorada nos relatos dos entrevistados e na literatura acadêmica, a autora delineia uma diferenciação entre as periferias paulistas e as favelas cariocas, evidenciado que ser periférico em São Paulo é está distante não só simbolicamente, mas também geograficamente da região central onde se acessa os serviços públicos e as oportunidades. Observa também que, assim como as periferias são complexas e plurais, compostas por diversas classes sociais e singularidades, são também os sentidos atribuídos sobre essas localidades.

Parte dessa compreensão deriva do entendimento das periferias como territórios ocupados por atores que estabelecem redes de relações singulares, marcadoras de suas identidades enquanto sujeitos sociais construtores das realidades onde vivem. Desse processo também resulta no contexto histórico contemporâneo, a construção da ressignificação da periferia como território de orgulho e pertencimento por parte dos Sujeitos Periféricos. Os jornalistas profissionais das iniciativas estudadas, segundo Rovida, inserem-se nesse processo mais amplo de transformação material e simbólica dessas realidades.

Demarcado o entendimento que faz das periferias, Rovida parte para o ponto central e de maior fôlego do seu trabalho. Intitulado Jornalismo das Periferias, o terceiro capítulo é voltado a identificar e sistematizar as características desse jornalismo, no que concerne à sua forma de organização e gestão, rotina produtiva, condições de trabalho, política editorial. Destaca-se que, pelas dificuldades de sustentabilidade financeira das iniciativas, o trabalho é feito muitas vezes de forma voluntária e paralela a atividades que

\section{Revista ALTERJOR}

Grupo de Estudos Alterjor: Jornalismo Popular e Alternativo (ECA-USP)

Ano 11 - Volume 02 - Edição 24 - Julho-Dezembro de 2021 Av. Professor Lúcio Martins Rodrigues, 443, Cidade Universitária, São Paulo, CEP: 05508-020 


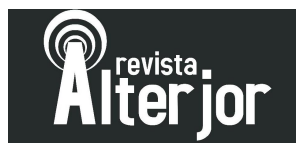

garantam outras fontes de renda. A manutenção dos arranjos comunicativos, apesar das adversidades, está ligada à expectativa profissional de fazê-los prosperar, associando a estabilidade financeira à satisfação pessoal em fazer parte de um movimento mais amplo de democratização social.

De acordo com a autora, várias formas de financiamento são buscadas para esse fim, desde participação em editais públicos, assinaturas da audiência, doações. Uma reivindicação coletiva dos/as profissionais é a construção de editais públicos específicos para a área da Comunicação. Até o momento os/as jornalistas têm participado apenas dos editais culturais, que dão ênfase à produção de produtos pontuais. Isso os impede de obter apoios financeiros mais longevos, que permitiriam planejamento produtivo a médio e longo prazos. Também em razão da busca por financiamento público, o conceito de "coletivo", que define a busca desses profissionais por gerarem relações de trabalho horizontais e colaborativas, vem sendo substituído por outras terminologias, como Agência, Produtora ou Associação de Jornalismo. Segundo os sujeitos de pesquisa, essas terminologias ofertam um sentido "menos ativista" e "mais profissional" ao trabalho desenvolvido, o que ajuda na obtenção de recursos públicos. Disso resulta também uma discussão importante mobilizada no trabalho: o de ativismo e profissionalismo; o que desemboca no esforço de Rovida em ouvir os sujeitos de pesquisa sobre os entendimentos que possuem em relação aos conceitos de Jornalismo Alternativo e Mídia Radical, por exemplo.

Segundo o relato dos entrevistados, preceitos jornalísticos relacionados à checagem e ao apartidarismo são seguidos em suas produções, mesmo que as condições de trabalho não sejam ideais. Isto é, não deixam de realizar apuração in loco, garantindo a qualidade e credibilidade da produção, ainda que não possuam sede própria ou remuneração para realizar o trabalho coletivo. Além disso, essas iniciativas configuramse como um processo formativo paralelo, onde os jornalistas mais experientes compartilham e trocam saberes com os mais novos, por meio de rotinas de trabalho que estimulam a construção colaborativa das matérias e/ou da realização de oficinas específicas para fins pedagógicos. É possível refletir que isso se dá, em parte, porque esse jornalismo é composto em grande medida por jornalistas em formação, recém-formados,

\section{Revista ALTERJOR}

Grupo de Estudos Alterjor: Jornalismo Popular e Alternativo (ECA-USP)

Ano 11 - Volume 02 - Edição 24 - Julho-Dezembro de 2021 Av. Professor Lúcio Martins Rodrigues, 443, Cidade Universitária, São Paulo, CEP: 05508-020 


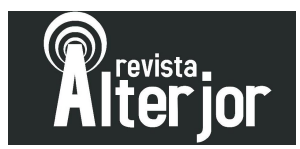

ou ainda sem formação na área; em outra, porque sua forma de organização é pautada na horizontalidade e na colaboração.

A política editorial dos arranjos também se destaca pela sua pluralidade no processo de caracterização do fenômeno. Apesar de todas as iniciativas estudadas serem marcadas pelo recorte periférico, cada uma define à sua maneira o que será pauta nas produtoras de Jornalismo. Classe, gênero e raça entrecortam essas escolhas. As formas de contar as histórias também são variadas. Assim sendo, segundo os sujeitos de pesquisa, de forma conjunta e cumulativa o trabalho produzido pelas iniciativas é marcado pela complementariedade de ações na busca por criar histórias múltiplas sobre as periferias e garantir o acesso aos seus cidadãos ao Direito à Informação.

Após intensa sistematização de informações sobre o fenômeno estudado, Rovida (2020, p. 154) se dedica no quarto capítulo - Os jornalistas das periferias - a construir um esboço do perfil coletivo dos sujeitos de pesquisa, a partir da trajetória de vida e profissional que narraram possuir ao longo da pesquisa. Em um texto potente, que evidencia as desigualdades e superações sociais relativas ao acesso à educação formal no Brasil e ao mercado de trabalho, a autora costura vários pontos importantes destacados na história desses profissionais para, "sem identificar um protagonista específico, apresentar a experiência dos jornalistas das periferias da RMSP”. Do esboço é possível compreender em significativa medida o que os motiva, os transforma e impulsiona a construírem o Jornalismo das Periferias.

Já O ponto de chegada, último capítulo do livro, configura-se como uma síntese de algumas das principais questões descobertas durante a pesquisa - algumas delas mencionadas nessa resenha. O conceito de Diálogo Social Solidário, fundamentado por Mara Rovida em estudo anterior, a partir da ideia de Solidariedade Orgânica de Émile Durkheim e de Dialogia Jornalística em Cremilda Medina, foi acionado em várias partes da obra para compreender as relações de trabalho entre os jornalistas em questão, bem como entre eles e outros Sujeitos Periféricos das realidades que noticiam. Do estudo, evidenciou-se que uma rede de solidariedade é forjada entre um conjunto de coletivos e sujeitos pertencentes a eles, bem como que o jornalismo, enquanto mediador social,

\section{Revista ALTERJOR}

Grupo de Estudos Alterjor: Jornalismo Popular e Alternativo (ECA-USP)

Ano 11 - Volume 02 - Edição 24 - Julho-Dezembro de 2021 Av. Professor Lúcio Martins Rodrigues, 443, Cidade Universitária, São Paulo, CEP: 05508-020 


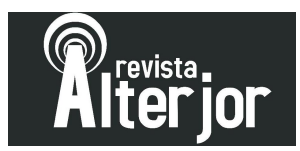

favorece por meio do seu potencial dialógico, que essa rede se amplie, fomentando a autoestima periférica e colaborando para a democratização social.

\section{REFERÊNCIA}

ROVIDA, Mara. Jornalismo das periferias: o diálogo social solidário nas bordas urbanas. Curitiba: CRV, 2020. 